\title{
Fronteiras e esquecimento: Noite dentro da noite, de Joca Reiners Terron
}

\author{
Borders and Oblivion: Noite dentro da noite, by Joca Reiners Terron \\ Fronteras y olvido: Noite dentro da noite, de Joca Reiners Terron
}

Cristiane Checchia*

\begin{abstract}
Resumo
Parte da literatura brasileira contemporânea evidencia um vigoroso esforço na luta contra o esquecimento sobre o período da ditadura civil-militar vivida entre os anos 1964 e 1985 . Entre tal produção, encontramse os trabalhos de uma nova geração de escritores que lidam com os restos do passado a partir, muitas vezes, do registro autobiográfico, de olhares permeados pela distância e pela perspectiva infantil. Em alguns desses relatos, a presença de personagens viajantes, desterritorializados, e deslocando-se entre fronteiras e idiomas parecem sugerir que o trabalho da memória se aprofunda a partir do trânsito, do caminhar e de desvios que frequentemente eludem os limites impostos por barreiras identitárias e de nacionalidade. É a partir dessa percepção e de uma reflexão sobre os conflitos em torno das memórias do último ciclo de ditaduras do Cone Sul que proponho a leitura de Noite dentro da noite (2017a), de Joca Reiners Terron. Apresentado como uma autobiografia, o romance é narrado pelo personagem Curt MeyerClason, o conhecido tradutor de Guimarães Rosa para o alemão. É esse narrador misterioso que lentamente enlaça a infância do protagonista amnésico ao passado recente do Brasil e do Paraguai sob ditaduras. Tal proposta de leitura é inevitavelmente atravessada pelo atual contexto de esgarçamento do horizonte democrático contemporâneo.
\end{abstract}

Palavras-chave: memória, esquecimento, fronteiras, escritas de si, Joca Reiners Terron.

\begin{abstract}
Part of contemporary Brazilian literature shows a vigorous effort in the fight against forgetfulness about the period of the civil-military dictatorship lived between 1964 and 1985. Among this production are the works of a new generation of writers who deal with the remains of the past, often from autobiographical record, from points of view permeated by distance, and the perspective of children. In some of these accounts, the presence of traveling characters, deterritorialized and moving between borders and languages, seems to suggest that the work of memory is built from walking and detours that often evade the limits imposed by barriers of identity and nationality. It is from this perception and from a reflection on the conflicts around the memories of the last cycle of dictatorships in the Southern Cone that I propose a reading of Noite dentro da noite (2017a), by Joca Reiners Terron. Presented as an autobiography, the novel is narrated by the character Curt Meyer-Clason, the well-known translator of Guimarães Rosa into German. It is this mysterious narrator who slowly
\end{abstract}

\section{Resumen}

Parte de la literatura brasileña contemporánea muestra un vigoroso esfuerzo en la lucha contra el olvido sobre el período de la dictadura cívico-militar vivido entre 1964 y 1985. Entre esta producción se encuentran las obras de una nueva generación de escritores que se ocupan de los restos del pasado, a menudo del registro autobiográfico, de las miradas impregnadas de distancia y de la perspectiva de los niños. En algunos de estos relatos, la presencia de personajes viajeros, desterritorializados y que se desplazan entre fronteras e idiomas, parece sugerir que la obra de la memoria se construye a partir del caminar y de los desvíos que a menudo evaden los límites impuestos por las barreras de la identidad y la nacionalidad. Es a partir de esta percepción y de una reflexión sobre los conflictos en torno a los recuerdos del último ciclo de dictaduras en el Cono Sur que propongo la lectura de Noite dentro da noite (2017a), de Joca Reiners Terron. Presentada como una autobiografía, la novela es narrada por el personaje Curt Meyer-Clason, el conocido traductor de Guimarães Rosa al alemán. Es este misterioso narrador quien vincula lentamente la infancia del

\footnotetext{
* Universidade Federal da Integração Latino-Americana (Unila), Foz do Iguaçu, PR, Brasil. (Dorcid.org/0000-0002-3039-0463. E-mail: crischecchia@gmail.com
} 
links the childhood of the amnesic protagonist to the recent past of Brazil and Paraguay, both under dictatorship. Such a reading is inevitably cut through by the current context of fragmenting the contemporary democratic horizon.

Keywords: memory, forgetfulness, borders, selfwritten, Joca Reiners Terron. protagonista amnésico con el pasado reciente de Brasil y Paraguay bajo dictaduras. Esta propuesta de lectura está atravesada inevitablemente por el contexto actual de fragmentación del horizonte democrático contemporáneo.

Palabras-clave: memoria, olvido, fronteras, escrituras del sí, Joca Reiners Terron.

\section{Sobre lembrar e esquecer}

Foram inúmeras e são conhecidas as dificuldades enfrentadas no Cone Sul latino-americano, ao longo dos anos 1980 e 1990, para converter os processos da chamada transição à democracia formal após as ditaduras em um processo efetivamente democrático. De um modo geral, as comunidades políticas nesses países enfrentaram-se com fortes resíduos ideológicos difundidos socialmente e mecanismos de inércia institucional, além da perpetuação de práticas de violência ilegal que resistiam ao contexto de abertura. Desde o final do ciclo ditatorial até o presente, contudo, as demandas pelo direito à memória, por justiça e reparação movidas por distintos atores sociais têm sido um meio importante de enfrentamento a tais tendências inerciais. Se este pode ser visto como um quadro geral de toda a região, é notável como há muitas especificidades na forma como se deram tais enfrentamentos e nos resultados alcançados em cada um dos países. ${ }^{1}$

No caso do Brasil, parece consenso o fato de se haver instaurado entre nós uma série de obstáculos à memória, verdadeira máquina do esquecimento, ${ }^{2}$ que se evidencia de inúmeras maneiras ou, seria possível dizer, por meio de inúmeros sintomas: ainda hoje há estradas, ruas, cidades e escolas batizadas com o nome de militares que exerceram o poder durante a ditadura; pouquíssimos memoriais foram erguidos no Brasil para lembrar as vítimas do regime; apesar dos esforços fundamentais da Comissão de Familiares de Mortos e Desaparecidos Políticos, o debate em torno da apuração dos casos e dos responsáveis pelos crimes cometidos em nome do Estado foi visto durante anos como um tema que não pertencia à esfera pública; não por acaso, o país foi o que mais tardiamente instaurou sua Comissão Nacional da Verdade, cujo relatório foi entregue de forma bastante discreta à sociedade brasileira em dezembro de 2014; talvez apenas por uma ou duas exceções, militares reconhecidamente responsáveis por crimes permanecem impunes.

Ao contrário dos processos de elaboração simbólica, como o luto, que permitem o jogo entre o lembrar e o esquecer para seguir-se adiante, o processo que se impôs no contexto pósditatorial brasileiro parece combinar duas formas de esquecimento, na classificação de Ricoeur: o "esquecimento obrigatório" (esquecimento institucional que prevalece nos casos de anistia forçada) relacionado ao "esquecimento como memória impedida", que mantém o trauma em uma zona de recalque, compelindo à repetição (Ricoeur, 2018). Seria possível pensar a partir daí no esquecimento como uma forma ativa de violência, que faz perdurar os efeitos de um sofrimento que não encontra canais coletivos de reconhecimento e que tende a se agravar com o passar do tempo, manifestando-se como sintoma social em práticas e discursos automatizados que seguem empurrando para longe os limites de simbolização dos traumas (Kehl, 2010, p. 128).

É evidente que a facilidade com que foi acionada essa máquina de esquecer tem a ver com o modelo institucional e com a forma de operar dos governantes militares no Brasil, que mantiveram evidentes laços de colaboração com parcelas importantes da elite econômica e da elite política civil ao longo de todo o período em que estiveram no poder. Assim, sua atuação

\footnotetext{
${ }^{1}$ Uma versão preliminar deste texto e ainda com pontos por desenvolver foi apresentada no I Congreso Internacional Pensamiento e Investigación sobre América Latina (CIPPAL), em 2019.

${ }^{2}$ Márcio Seligmann-Silva tem trabalhado sobre as dinâmicas singulares do processo de disputa pela memória no Brasil. Estas considerações iniciais se fazem com base em uma síntese de distintos textos do autor $(2006 ; 2011 ; 2014 ; 2015)$, os quais, escritos ao longo dos últimos anos, permitem acompanhar as lentas conquistas que se foram fazendo nesse terreno.
} 
aparentemente mais discreta ${ }^{3}$ e articulada com os setores dominantes, permitiu não apenas a manutenção de uma máscara legalista nos sucessivos governos militares, como também lhes permitiu controlar com mais desenvoltura os arranjos do processo de redemocratização. $O$ resultado disso foi a imposição de uma série de soluções de continuidade, como a manutenção de aparelhos repressivos e das formas ilegais de violência do Estado, a proeminência política de reconhecidos apoiadores do regime e a implementação da asfixiante lei da Anistia (Zular, 2015, p. 108-110; Pinheiro, 1991, p. 45 e 51).

Assim, se na Argentina foi possível assistir ao surgimento de um acalorado debate em torno da hipótese de um excesso de memória, ${ }^{4}$ para nós, no Brasil, essa polêmica simplesmente não teria lugar, dada a exasperante morosidade com que o tema da memória abre espaços na esfera pública.

Há desdobramentos visíveis desse processo também no campo artístico e literário, como não poderia deixar de ser. Existe, reconhecidamente, uma vigorosa literatura que lidou com os traumas do passado ditatorial recente no Cone Sul, tanto de caráter mais estritamente testemunhal quanto de caráter ficcional (essa divisão nem sempre é simples de ser feita, como será visto mais adiante). Mas, se essa literatura teve um espaço de recepção muito importante em países como Argentina, Chile e Uruguai ao longo dos anos 1980 e 1990, no Brasil, essa produção, menos numerosa, teve sempre uma acolhida bastante tímida. Conforme salientou Seligmann-Silva (2011), mesmo quando os testemunhos e relatos são publicados, eles são muito eficientemente anulados por uma ausência de recepção: desacreditados como "revanchistas", são vistos como resquícios indesejados de um passado do qual já se deveria ter virado a página.

Apesar de todo o quadro traçado acima, que descreve a ausência de uma cultura da memória no Brasil e a existência de mecanismos pelos quais nosso passado ditatorial permanecia à sombra, é possível também lançar luz sobre os significativos exemplos na produção literária brasileira contemporânea de uma resiliente luta contra o esquecimento, assumida agora por uma geração de escritores que trabalham com os restos do passado a partir, muitas vezes, do registro autobiográfico e de olhares permeados pela distância e pela perspectiva infantil. São escritores da "segunda geração", que viveram biograficamente o período ainda quando crianças e que imprimem as marcas dessa distância em seus escritos. Enfrentam assim em sua escrita o duplo desafio de lembrar o passado recente, mas também focar os olhos no presente, formulando suas próprias perguntas para a construção de caminhos de criação artística (Schøllhammer, 2004, p. 13).

Nos relatos com que tenho buscado trabalhar, o deslocamento entre idiomas, o fluxo entre cidades e o exílio e a experiência dos confins/fronteiras parecem mostrar que o trabalho da memória se erige a partir dos deslocamentos, do caminhar e de desvios que frequentemente eludem os limites impostos por barreiras identitárias e de nacionalidade. Assim, se, por um lado, as singularidades dos processos históricos e políticos no âmbito de cada país do Cone Sul demandam de nós o contraste entre as distintas culturas nacionais da memória (ou a quase ausência de uma, no caso do Brasil), por outro lado, tais relatos nos convocam a desenhar outros mapas, cujos limites e fronteiras se mostram bastante mais porosos, e que poderiam ser vistos de uma perspectiva de memórias em trânsito (Erll, 2011; Huyssen, 2014). ${ }^{5}$

Portanto, é com esse olhar que tenho me debruçado sobre alguns romances, ${ }^{6}$ somando-me a um movimento crítico que tem buscado pensar uma memória compartilhada em um mapa

\footnotetext{
${ }^{3}$ Palavra que só resiste na comparação numérica das vítimas civis do regime, em relação aos nossos vizinhos.

${ }^{4}$ Desenvolvi mais longamente este tema no artigo “Disputas pela memória no ensaio argentino: o incômodo 'Invierno', de Juan José Saer" (Checchia, 2018).

5 Ambos os autores assinalam o fato de que durante muito tempo perdurou nos estudos da memória um viés metodológico marcadamente nacionalizante, isto é, preocupado sobretudo com a organização dos processos de configuração de memórias no âmbito das construções identitárias nacionais. Os estudos pós-coloniais foram importantes para chamar a atenção para memórias viajantes, transculturais, ou multidirecionais, frutos de processos diaspóricos e de deslocamentos de diversas ordens (linguísticos, territoriais, afetivos). Essa perspectiva se fortaleceu, a partir de finais do séc. XX e da multiplicidade dos processos implicados no contexto da globalização econômica.

${ }^{6}$ Um primeiro corpus de autores foi desenhado na pesquisa "Histórias em trânsito de um passado insepulto - memórias da ditadura argentina em três romances brasileiros contemporâneos”, apresentado no IX Congresso Brasileiro de Hispanistas em 2016.
} 
histórico-político-cultural-literário-afetivo ampliado, e é nesse conjunto que procuro inserir a leitura de Noite dentro da noite, de Joca Reiners Terron (2017a)..$^{7}$ Neste trabalho, interessa-me investigar a construção da paisagem da fronteira e a presença das personagens indígenas de diferentes etnias (Guaranis-Mbya, Ava-Guaranis, Kadiweus, Chamacocos e Bororos) que aparecem ao longo do romance de forma ao mesmo tempo tangencial e estrutural, na medida em que sua cosmovisão é trabalhada na organização temporal e no próprio desenvolvimento do enredo. Pensa-se assim a presença invisibilizada e esquecida desses grupos nos diferentes momentos da brutal expansão sobre as fronteiras entre o extremo oeste brasileiro e o Chaco boreal paraguaio, sobretudo no período das ditaduras dos dois lados da fronteira.

\section{Noite dentro da noite - romance autobiográfico?}

Joca Reiners Terron é autor de obras em diversos gêneros: poesia, contos, romances, grafic novel, ensaios e roteiros. De sua trajetória, interessa sublinhar um trânsito intenso como leitor de uma vertente da literatura brasileira bastante experimental (como Valêncio Xavier, de O mez da grippe; Sebastião Nunes, de História do Brasil e Decálogo da classe média; além de Raduan Nassar e José Agrippino de Paula), bem como da literatura hispânica contemporânea menos conhecida no país. Como organizador da coleção Otra Língua, da editora Rocco, Terron visibilizou alguns nomes até então ainda pouco lidos em português, somando-se aos esforços realizados reconhecidamente pelo editor Samuel Leon. Desse modo, autores como Ricardo Piglia, Juan José Saer, César Aira, Sylvia Molloy, Copi, Fabián Casas, Washington Cucurto e Guadalupe Nettel perfazem a estante de um leitor cuja trajetória se desenvolve em um trânsito entre línguas que sua própria escrita promoverá também de outros modos.

Apresentado como uma autobiografia, o romance Noite dentro da noite narra a trajetória de um menino que cresceu deslocando-se entre cidades do extremo Oeste do Paraná e do Mato Grosso do Sul, na fronteira com o Paraguai, entre os anos 1970 e 1980, até sua juventude no Rio de Janeiro. Como elemento de tensão central do relato, que dará impulso à narrativa logo em seu início, vemos a descrição de um acidente sofrido pelo personagem durante uma brincadeira na infância, na cidade paranaense de Medianeira: ao bater fortemente a cabeça em uma pilastra de concreto e quase perder a vida, o menino sofrerá de uma amnésia profunda, seguida de convulsões que serão por anos tratadas à base de barbitúricos. Ele perderá também a fala e a capacidade de reconhecer-se em sua família. Toda a narrativa, portanto, parece ser acionada por este esforço de superação do esquecimento: o marco do relato será o "Ano do grande branco", explicitamente localizado em 1975.

Se muitos elementos da trajetória desse protagonista de fato coincidem com as marcas biográficas do autor fora do texto, por outro lado, desde o início somos defrontados com mecanismos que tornam instáveis a leitura gerada pela expectativa de uma autobiografia (Arfuch, 2009). ${ }^{8}$ Primeiramente, a história é narrada ao protagonista na inusual segunda pessoa pelo personagem Curt Meyer-Clason, nada menos que o conhecido tradutor de Guimarães Rosa para o alemão. Acusado de espionagem para o III Reich, Meyer-Clason foi preso em 1942 e passou cinco anos preso no presídio da Ilha Grande, período durante o qual entrou em contato com a literatura. Sem nunca ter admitido a acusação da qual foi alvo, essa figura interessa como narrador deste romance por "ter tido uma vida dentro de outra vida" (Terron, 2017b, s.p.): "será esse narrador misterioso quem irá narrar a vida de outro em uma língua que lhe é estrangeira, enlaçando lentamente a infância e juventude do protagonista ao passado recente do Brasil e do Paraguai, e a todo o mosaico de guerras e ditaduras que atravessam o séc. XX".

\footnotetext{
${ }^{7}$ Doravante, todas as vezes em que for citado o romance, tratar-se-á desta mesma edição.

8 Para pensar a expansão do registro autobiográfico no presente, em múltiplas plataformas, a crítica argentina Leonor Arfuch desenvolveu a noção de espaço autobiográfico. A autora parte da notável profusão de best-sellers (auto)biográficos, da multiplicação de publicações dedicadas a exposição da vida de celebridades, ou, mais recentemente, do fenômeno impressionante dos blogs e relatos ilustrados de si nas redes sociais, para se perguntar sobre os significados possíveis dessa expansão (Arfuch, 2009). Este quadro torna ainda mais instigante a leitura dos relatos autobiográficos ou autoficcionais que têm surgido na cena literária latino-americana recente, notadamente desde finais do século passado, dialogando com a tradição do romance de formação, mas transgredindo-os.
} 
No entanto, essa voz narradora é emoldurada e sobreposta mais tarde por outra voz, também em segunda pessoa, que se instaura em uma zona incerta interior e exterior ao relato. Não se pode saber quem termina por narrar o que o protagonista escuta como sua autobiografia: "Esse protagonista do livro tratado apenas por "você" está vazio de existência, pois não se lembra dela. Então recorre a outras pessoas, que a contam para ele. Além disso, é mudo. Como mudo, não poderia narrar a própria história. Aos personagens mudos está vetada a primeira pessoa" (Terron, 2017d, s.p.).

O protagonista é, então, o que "não fala", como se os confusos e fragmentários restos do passado o seguissem oprimindo e não pudessem ser transformados em discurso, em memória. Um processo de elaboração de seu passado parece estar engasgado pela impossibilidade de vencer os fantasmas que o assombram e que o impedem de se reconhecer como indivíduo e somente o auxílio de outros narradores pode ajudá-lo na tarefa impossível de elaboração de um relato de si.

Nesse sentido, Noite dentro da noite aproxima-se de outras práticas literárias e artísticas autobiográficas contemporâneas, mas haveria que se diferenciar os caminhos que se podem encontrar entre tais práticas: enquanto alguns desses relatos parecem apoiar-se na retomada da confiança de uma subjetividade expressiva que rompe os pudores que perduravam com a decretação da morte do autor dos anos 1960 (como o Filho eterno, de Cristóvão Tezza), outra vertente de relatos parece dobrar a aposta na suspeita sobre a possibilidade de configuração do sujeito como unidade psicológica prévia à escrita (Schøllhammer, 2009, p. 109-110). Noite dentro da noite estaria certamente entre as obras desta segunda tendência que, embora inscritas em um contexto de hiperinflação das narrativas do eu e de celebração do self, e ainda que flertando com a tradição do romance de formação, trabalham paradoxalmente na dissolução das noções de sujeito e indivíduo. Comentando as produções autoficionais brasileiras contemporâneas, Diana Klinger fala de uma ilusão de presença, na qual o sujeito da escrita não é um ser pleno, como na propalada morte do autor barthesiana, mas que, diferente desta, faz com que o autor reapareça como resultado de uma construção que opera tanto dentro quanto fora do texto ficcional, implicando em uma dramatização de si que, ainda na esteira das tradições filosóficas críticas à Modernidade, corrói por outros meios a substancialidade da categoria sujeito (Klinger, 2012, p. 49 e ss.). No romance que temos em vista, a sobreposição de vozes narradoras reforça a estrutura abismal do relato e a impossibilidade de uma "autobiografia": histórias dentro de histórias diluem a identidade das personagens em uma zona pantanosa, movediça, mutante, fronteiriça. Essa dissolução se produz tanto no entrelaçamento de diversas camadas temporais como na inscrição peculiar que os múltiplos fios do relato estabelecem com o espaço.

Do ponto de vista da organização temporal, o relato fragmentário e nebuloso de diferentes capítulos da história do protagonista se estabelece por idas e vindas em uma cronologia impossível, cujos tempos se interrompem e se interpelam. A estrutura narrativa do romance parece espelhar-se na imagem da capa ${ }^{9}$ (Hole, de Brendan Monroe, 2012), a qual, por sua vez, remeteria ao Maeström, grande turbilhão de água que atrai tudo que se aproxima ao seu epicentro entrópico (como no conto de Edgar Allan Poe "Uma descida ao Maelström"). Relaciona-se também com a concepção mbya-guarani da passagem do tempo e da ideia de amanhã, segundo comentou Terron (2017c). Essa ideia aparece apenas como uma breve menção do autor, que demandaria uma investigação mais cuidadosa. No entanto, procurando algumas pistas de como a concepção de tempo guarani pode ser estruturante do romance vale recorrer ao antropólogo Bartolomeu Meliá. ${ }^{10}$ Ele mostra como a noção de história dos guaranis é uma articulação profunda entre as categorias de espaço e tempo: a composição dos cantos guaranis é a rememoração de suas caminhadas, uma memória fortemente espacializada, portanto. Mas a história de um guarani é também pensada a partir das palavras ao longo do tempo. O tempo é a história das palavras escutadas, das palavras ditas, das palavras inspiradas, das palavras rezadas, das palavras pronunciadas em uma assembleia, das palavras sussurradas na vida íntima (Meliá, 2010).

\footnotetext{
${ }^{9}$ Tendo cursado arquitetura, Joca Reiners Terron é também artista gráfico. As imagens de capa, as intervenções na página e as imagens no interior de seus relatos não se configuram apenas como elementos paratextuais marginais, mas são parte importante da composição.

${ }^{10}$ Agradeço à Mayra Moreyra a indicação desta referência.
} 
Essa ideia parece de fato produtiva para pensar a estrutura do romance que se faz da costura de relatos que o protagonista ouve de esquivos narradores. A vida deste personagem é assim atravessada e se dilui em uma temporalidade muito ampla, que a conecta, pelo que ouve e lê em suas longas viagens, aos múltiplos períodos de guerras locais, regionais e mundiais que repercutem em uma vida: a alta dosagem de barbitúricos a que o menino é submetido para tratamento de suas crises epilépticas, por exemplo, é conectada ao cenário de horror do Centro de Eutanásia de Bernburg, o conhecido laboratório onde se testaram os medicamentos para o assassinato em massa de crianças com deficiências físicas ou mentais, medicamentos os quais se popularizaram pela indústria farmacêutica para tratamento de ocorrências neurológicas. A estrutura vertiginosa do romance também parece ecoar, às vezes, os efeitos atordoantes dos medicamentos, sobrepostos aos efeitos da amnésia. A impossibilidade de fala do protagonista, portanto, mais do que apenas a um trauma individual, parece remeter à experiência violenta de múltiplas catástrofes coletivas sobrepostas no tempo, que rompem a confiança dos sujeitos nas regras estabelecidas da comunicação e do uso da linguagem.

Do ponto de vista espacial, por sua vez, um dos núcleos geográficos importantes da narrativa é a zona de fronteira entre o Brasil, estado do Mato Grosso do Sul, e o Paraguai, para onde o personagem protagonista seguiu com os pais após o acidente que lhe tirou a memória. Nesse sentido, o romance desenha uma zona, uma paisagem geográfica e linguística de fronteira que até recentemente permanecia bastante à sombra na tradição literária brasileira.

\section{Entre Brasil e Paraguai, as fronteiras esquecidas de uma história brutal}

A valorização desta zona fronteiriça na literatura do autor acompanha um movimento verificável em múltiplas linguagens artísticas do presente que têm experimentado o potencial de descobertas estéticas, cognitivas e políticas das fronteiras, como umbrais que desorganizam os limites entre línguas, entre linguagens, entre nações, entre áreas do saber, configurando espaços de trânsitos interculturais, intergêneros, intersubjetivos (Arfuch, 2013, p. 119-120; Garramuño, 2014).

No caso de Noite dentro da noite, resistente a qualquer possibilidade de romantização, sua fronteira remete também à história traumática das áreas de expansão nacional sobre territórios indígenas, militarizadas, embrutecidas, nas quais a violência pública e socialmente capilarizada frequentemente esmaga a intimidade dos sujeitos..$^{11}$ Nesse espaço, o protagonista do romance é mostrado em permanente desajuste com o território. A cidade denominada Curva de Rio Sujo, onde o menino conviverá com filhos de militares brasileiros e paraguaios, configura-se como um ambiente que reproduz no cotidiano escolar e nos caminhos marginais à beira do rio, entre a casa e a escola, a violência extrema que se impunha no cenário mais amplo dos dois países sob ditadura.

Ainda que ficcional, a cidade de Curva de Rio Sujo carrega as marcas referenciais de Bela Vista, uma cidade de cerca de duzentos anos na fronteira com o Paraguai, a qual, segundo Terron, "ainda rumina restos de uma guerra acontecida há mais de cem anos" (2017c, s.p.). No livro de contos Curva de Rio Sujo (Terron, 2003a), que esquadrinha esta mesma paisagem, o gesto predominante do autor parecia ainda bastante norteado pelo esforço de registro e de denúncia social, mais próximo à tradição regionalista, ainda que mobilizando alguns experimentos formais que instigavam outro tipo de leitura. ${ }^{12}$ Já em Noite dentro da noite, a escrita do território que prevalecia nos contos de Curva de Rio Sujo (Terron, 2003a) parece dar lugar ao território da escrita. Longe de puro exercício vazio com as formas, porém, a estrutura fragmentária e elíptica do

\footnotetext{
${ }^{11} \mathrm{O}$ texto já clássico ainda que talvez pouco conhecido de José de Souza Martins sobre as fronteiras é especialmente produtivo para dialogar com o texto literário de Terron. Martins trabalha com a ideia de que a fronteira, ou a frente conflitiva de expansão da sociedade nacional sobre os territórios indígenas, seja talvez o cenário em que mais explicitamente se evidencia a disputa pela definição do humano. A fronteira não se resume de modo algum à fronteira geográfica. Trata-se da fronteira de diferentes esferas: a fronteira espacial; a fronteira de culturas e visões de mundo; a fronteira de etnias; a fronteira das histórias e das diferentes historicidades; a fronteira do humano (Martins, 1997, p. 12-13).

${ }^{12}$ Como no conto "Monarks atravessam o Apa" (Terron, 2003b, p. 33-39), que deu origem ao filme Não devore meu coração (2017), dirigido por Felipe Bragança.
} 
romance e sua resistência à atribuição de sentidos lineares colocam em evidência de um modo inédito as práticas violentas socialmente enraizadas nessas bordas de território, que vão além do período de excessão e deitam raízes profundas no passado da região.

Assim, a paisagem é inquirida em sua singularidade histórica e geográfica, mas é explorada também como zona de investigação das fronteiras entre o humano e o não humano, empurrando os horizontes da escrita para um questionamento sobre as origens do mal. No jogo intertextual que o romance estabelece sobrepondo distintos relatos sobre a região inscrevem-se camadas mais profundas de conflitos: embora a cidade de Curva de Rio Sujo seja geolocalizada de forma bastante específica no romance, ela parece configurar-se como o epicentro de uma fronteira ampliada que inclui os cenários da Guerra da Tríplice Aliança contra o Paraguai, os experimentos de uma colônia ariana por alemães antissemitas em finais do século XIX no Chaco Paraguaio e os confrontos entre conquistadores e indígenas em meio aos pântanos na época da Conquista e nos períodos posteriores de expansão da fronteira oeste brasileira e da fronteira leste paraguaia.

Todos esses diferentes períodos de atrocidades são vistos à luz da violência experimentada no corpo pelo menino protagonista, perseguido diariamente pelos colegas filhos de militares paraguaios em meados dos anos 1970. É nessa zona de fronteira que circulam diferentes grupos indígenas de diferentes etnias (guaranis-Mbya, Ava-Guaranis, Kadiweus, Chamacocos e Bororos) que aparecem ao longo do romance. A voz do(s) narrador(es) múltiplo e esquivo que os descreve parece bastante presa a uma perspectiva ocidental, cujo efeito é o de estranhamento. O pantanal matogrossense e o Chaco paraguaio formam uma espécie de coração das trevas conradiano, habitado pelo selvagem bárbaro: os indígenas algumas vezes são mostrados como os míticos e exímios cavaleiros kadiwéus; outras vezes aparecem como grupos empobrecidos e miseráveis subjugados pelos fazendeiros, pelas doenças, pela pobreza e acossados por guerras que lhes são alheias. Essa distância, contudo, cede na sobreposição de algumas cenas: nessa fronteira, os personagens duplicados, que são e não são, os saltos temporais e geográficos, promovem um efeito de aproximação entre sujeitos distantes que vivem dores semelhantes, como o protagonista espancado violentamente pelos colegas e o menino nhandeva assassinado na beira do rio (essa duplicação poderia se estender em uma enorme cadeia).

Em Noite dentro da noite há na fronteira de Terron algo da estética das ruínas, que evoca a série de guerra de Goya, na qual homens, mulheres, crianças e velhos anônimos sofrem toda variedade de horrores. Trata-se de uma escritura que persegue a tradição dos arquivos do Mal e da Loucura que poderíamos reconhecer em Poe, Conde de Lautréamont, Céline e Bolaño. Assim, ao escrever uma resenha sobre A literatura nazista na América, de autoria de Roberto Bolaño, Terron se refere a um ensaio do autor chileno no qual ele afirma que "A América Latina foi o manicômio da Europa" (Bolaño apud Terron, 2019, s.p.). Toda a larga zona fronteiriça dos relatos de Terron parece ser assim a contraface dos projetos da Modernidade europeia, e os indígenas da região são as vítimas e testemunhas dessa falência no coração da América do Sul, enfrentando a história de insanidade que atravessa seus territórios. De certo modo, parecem guardar a chave de uma narrativa que não se deixa ver por inteiro. El diablo, imortal guerreiro kadiweu, parece ser o único personagem que domina a matéria (espécie de líquen) que dá ou suga a vida daqueles que entram em contato com ela, a pyhareryepypepyhare, a noite dentro da noite.

\section{Sobre as vidas precárias}

Entre os múltiplos e emaranhados fios que compõem a estrutura abismal do relato, gostaria ainda de destacar aquele que trata das performances artísticas da mãe do protagonista, denominada sempre como "a rata". Obcecada com a passagem do tempo, ela fazia uma série de experimentos químicos para a produção de obras por meio do congelamento instantâneo da água, instalações que durariam apenas poucos segundos. Tão importante como as obras eram os pontos escolhidos para as performances: "locais ermos usados para desova de desaparecidos, cemitérios de indigentes onde foram descobertos cadáveres em covas rasas, os cafundós do Araguaia habitados por esqueletos de pés cimentados" (Terron, 2017a, p. 303-304), aldeias indígenas de tribos massacradas por garimpeiros ou capangas de fazendeiros. Suas obras, que 
aparecem descritas pelo narrador a partir dos relatos de um repórter ou destes relatos reproduzidos pelo tio do protagonista, representavam corpos de presos submetidos às então novas tecnologias de tortura. Sua última escultura de gelo instantâneo, no entanto, mostrava mulheres com prolapso de útero, comum entre mulheres indígenas submetidas à escravidão, às longas horas de trabalhos forçados e à inanição (Terron, 2017a, p. 322).

Nas obras da mãe do protagonista, o estranhamento em relação aos indígenas que subsiste na voz do narrador parece ceder - como na projeção do espancamento do protagonista na morte do nhandeva - à evidência de uma "vulnerabilidade humana em comum" (Butler, 2006), ${ }^{13}$ e das múltiplas formas de violência que oprimem as vidas precárias no contexto de violência extrema (do avanço sobre territórios, das guerras, das ditaduras). Tais obras efêmeras da "rata", elaboradas como denúncia aos crimes da ditadura e à exploração extrema das populações indígenas, enfrentando todos os riscos implicados nesse gesto, são também a expressão de uma responsabilidade ética, de uma busca artística que se insurge como uma empatia imperiosa entre alteridades, assentada sobre as bases de uma resistência coletiva possível, ainda que no seio da derrota.

\section{Novamente, sobre lembrar e esquecer}

Vê-se, portanto, em Noite dentro da noite, um jogo atordoante de histórias dentro de histórias, de personagens que assumem diferentes vestes e vozes, em um território pantanoso, que fagocita seus habitantes e os inscreve em múltiplos tempos e relatos, de vozes narrativas que se sobrepõem umas às outras, em uma zona incerta e instável entre a vigília e o sonho, entre a lucidez e a loucura, entre vida e morte. É instigante pensar que o impulso inicial e o grande motor de todo o relato é o esquecimento: "a sua memória foi deformada pela imaginação, que preencheu lacunas deixadas pelo esquecimento com uma dança da mente que ocupou, de modo bastante natural, sua esburacada consciência dos fatos com a fantasia da invenção", diz o narrador ao protagonista (Terron, 2017a, p. 37). Em um texto anunciado como autobiográfico, trata-se do mito de origem de uma escrita ou da performance de origem de um escritor, ${ }^{14}$ mas também se trata de uma expressiva metáfora para pensar a literatura e a relação de nossas sociedades com o passado.

A perda da memória do personagem parece confundir-se numa imensa amnésia coletiva, que se sobrepõe às histórias violentas de um tempo recente e remoto. Incapacitado de lembrar, no entanto, resta ao protagonista recorrer a outras vozes e, a partir delas, imaginar. A imaginação surge assim como um recurso extremo e poderoso de insurgência contra o silêncio, contra a mudez e o esquecimento, participando de um esforço compartilhado e conectado das literaturas do Cone Sul na configuração de uma memória de nosso passado recente.

Encaminhando às considerações finais, caberia dizer que leituras como Noite dentro da noite têm sido inapelavelmente atravessadas pelo presente, no qual o silêncio que imperava na esfera pública brasileira para tratar do tabu dos crimes da ditadura civil-militar, e que começara a ser vencido apenas muito recentemente no Brasil (por exemplo, com o relatório da Comissão da Verdade e seu importantíssimo capítulo sobre a violência contra os indígenas), agora sofre uma reviravolta atordoante, em um movimento paradoxal de lembrança às avessas, que abriu a tampa do bueiro onde se escondiam os horrores, mas para valorizá-los em sua face mais sombria e invocá-los explicitamente como exemplos. As tentativas de silenciamento da memória foram substituídas de forma aterradora por uma revisão consagratória desse passado bruto.

Trata-se de uma mudança de época que não se imaginava possível há pouco tempo atrás. Não é casual que esse movimento seja acompanhado igualmente por um projeto de eliminação

\footnotetext{
${ }^{13}$ A condição de vulnerabilidade original, do desamparo que, ao nascer, nos faz depender do corpo, da voz e dos cuidados de outro, que nos constitui em nossa subjetividade.

${ }^{14}$ Conforme a sugestão de Diana Klinger, para quem a "autoficção também é comparável à arte da performance na medida em que ambos se apresentam como textos inacabados, improvisados, work in progress, como se o leitor assistisse 'ao vivo' ao processo da escrita" (2012, p. 51).
} 
de qualquer forma de diferença, retomando não apenas uma política assimilacionista em relação aos grupos indígenas, mas inclusive inflamando explicitamente a práticas de extermínio por diversos meios. Aparentemente, com a força incontornável de um monstruoso recalque, os conflitos emergem hoje das zonas de ocultamento em que haviam sido mantidos, e ganham uma visibilidade inesperada.

Nesse contexto, como disse Eduardo Viveiros de Castro (2019), os povos indígenas representam a resistência imanente contra os discursos e os projetos de destruição da diversidade, os quais exacerbam explicitamente a atitude plurissecular das elites governantes do país - resistência imanente na medida em que a própria existência desses povos pressupõe a sua resistência.

É evidente que a onda reacionária atualmente em curso diz respeito a um fenômeno mais amplo, extremamente complexo e multifatorial, cujas causas devem ser buscadas em diferentes tempos. Mas para o que venho procurando pensar a partir da literatura, algo que realmente chama a atenção é o fato de que a expansão dos movimentos que defendem hoje um estreitamento do ambiente democrático no Brasil se inscreve sobre o enorme silêncio que se impôs sobre os importantes esforços de lembrar os 21 anos terríveis de nossa história recente e de denunciar o autoritarismo socialmente sedimentado em nossa formação.

Entendo que a chave de leitura com que líamos os romances de memória e de esquecimento como Noite dentro da noite está mudando radicalmente nesse contexto e que tais leituras, perpassadas por materiais bastante heterogêneos, podem ser também uma das tantas frentes de batalha da literatura, da crítica e da docência no presente.

\section{Referências}

ARFUCH, Leonor (2009). O espaço biográfico na (re)configuração da subjetividade contemporânea. In: GALLE, H. et al. Em primeira pessoa: abordagens de uma teoria da autobiografia. São Paulo: Annablume; Fapesp; FFLCH/USP. p. 113-121.

ARFUCH, Leonor (2013). El umbral, la frontera. In: ARFUCH, Leonor. Memoria y autobiografia: exploraciones en los límites. Buenos Aires: Fondo de Cultura Económica. p. 119-133.

BUTLER, Judith (2006). Violencia, duelo, política. In: BUTLER, Judith. Vida precária: el poder del duelo y la violencia. Tradução de Fermín Rodríguez. Buenos Aires: Paidós. p.45-78.

CASTRO, Eduardo Viveiros de (2019). Brasil, país do futuro do pretérito: aula inaugural do CTCH, PUC-Rio. Rio de Janeiro. 14 mar. Disponível em: https:/ / bit.ly/2Uxkna9. Acesso em: 14 jul. 2019.

CHECCHIA, Cristiane (2018). Disputas pela memória no ensaio argentino - o incômodo "Invierno", de Juan José Saer. Remate de Males, Campinas, v. 37, n. 2, p. 697-719. jul./dez. Disponível em: https://doi.org/10.20396/remate.v37i2.8648795. Acesso em: 30 mar. 2019.

ERLL, Astrid (2011). Traumatic pasts, literary afterlives, and transcultural memory: new directions of literary and media memory studies. Journal of Aesthetics \& Culture, v. 3, maio. Disponível em: https:/ / bit.ly/3aBVErE. Acesso em: 27 mar. 2019.

GARRAMUÑO, Florência (2014). Frutos estranhos: sobre a inespecificidade na estética contemporânea. Rio de Janeiro: Rocco.

HUYSSEN, Andreas (2014). Culturas do passado-presente: modernismos, artes visuais, políticas da memória. Rio de Janeiro: Contraponto; Museu de Arte do Rio.

KEHL, Maria Rita (2010). Tortura e sintoma social. In: TELES, Edson; SAFATLE, Vladimir (Org.). O que resta da ditadura. São Paulo: Boitempo. p. 123-132.

KLINGER, Diana (2012). Escritas de si, escritas do outro: o retorno de autor e a virada etnográfica. 2. ed. Rio de Janeiro: 7Letras.

MARTINS, José de Souza (1997). Fronteira: a degradação do Outro nos confins do humano. São Paulo: Hucitec. 
MELIÁ, Bartolomeu (2010). A história de um guarani é a história de suas palavras. [Entrevista concedida a] Patrícia Fachin. Revista do Instituto Humanitas Unisinus, São Leopoldo, ano 10, n. 331, p. 5-11, 31 maio. Disponível em: https:/ / bit.ly/3aViQRZ. Acesso em: 20 maio 2019.

PINHEIRO, Paulo Sérgio (1991). Autoritarismo e transição. Revista USP, São Paulo, n. 9, p. 45-56. Disponível em: https:/ / bit.ly/2QI759H. Acesso em: 23 jun. 2019.

RICOEUR, Paul (2018). A memória, a história o esquecimento. Campinas: Editora Unicamp.

SCHØLLHAMMER, Karl Erik (2004). Prefácio. In: VIDAL, Paloma. A história em seus restos. São Paulo: Annablume.

SCHØLLHAMMER, Karl Erik (2009). Ficção brasileira contemporânea. Rio de Janeiro: Civilização Brasileira.

SELIGMANN-SILVA, Márcio (2006). A construção da memória do terror na Argentina. Revista USP, São Paulo, n. 70, jun./ago. p. 176-179. Disponível em: https:// bit.ly/39i9GxA. Acesso em: 5 jun. 2018.

SELIGMANN-SILVA, Márcio (2011). Testemunho, políticas da memória e o caso da desmemória da ditadura brasileira. Revista Palavra, ano 3, n. 2. Disponível em: https://bit.ly/3b3ydaW. Acesso em: 5 jun. 2018.

SELIGMANN-SILVA, Márcio (2014). Imagens precárias: inscrições tênues de violência ditatorial no Brasil. Estudos de Literatura Brasileira Contemporânea, Brasília, n. 43, p. 13-34. Disponível em: https:// bit.ly/2vEvUMu. Acesso em: 5 jun. 2018.

SELIGMANN-SILVA, Márcio (2015). Por uma memória ativa. Folha de S. Paulo, São Paulo, p. 3.26 jan. Disponível em: https://bit.ly/2U4exy1. Acesso em: 22 mar. 2018.

TERRON, Joca Reiners (2003a). Curva de Rio Sujo. São Paulo: Planeta.

TERRON, Joca Reiners (2003b). Monarks atravessam o Apa. In: TERRON, Joca Reiners. Curva de Rio Sujo. São Paulo: Planeta. p. 33-39.

TERRON, Joca Reiners (2017a). Noite dentro da noite. São Paulo: Companhia das Letras.

TERRON, Joca Reiners (2017b). Joca Reiners Terron lança em BH romance "Noite dentro da noite". [Entrevista concedida a] Pedro Antunes. Site UAI, Belo Horizonte, 9 abr. Disponível em: https:/ / bit.ly/33xsIP0. Acesso em: 24 maio 2019.

TERRON, Joca Reiners (2017c). Temos de escolher muito bem aquilo que fingiremos ser: uma entrevista com Joca Reiners Terron. [Entrevista concedida a] Camila Von Holdefer. 20 jun. Disponível em: https:// bit.ly/2U2ilzQ. Acesso em: 24 out. 2018.

TERRON, Joca Reiners (2017d). Livro de Joca Reiners reflete desencanto do autor com a contemporaneidade. [Entrevista concedida a] Nahima Maciel. Correio Braziliense, Brasília, 30 abr. 2017. Disponível em: https:// bit.ly/2Ukx0VP. Acesso em: 24 out. 2018.

TERRON, Joca Reiners (2019). Livro que destacou Bolaño satiriza literatura nazista na América. Folha de $S$. Paulo, São Paulo, 22 março. Disponível em: https://bit.ly/2xWzd2t. Acesso em: 30 mar. 2019.

ZULAR, Roberto (2015). Encaroçada de estrelas: alguns poemas de Paulo Henriques Britto e a transição democrática. In: SISCAR, Marcos; NATALI, Marcos (Org.). Margens da democracia: a literatura e a questão da diferença. Campinas: Editora da Unicamp; São Paulo: Edusp. p. 109-131. 